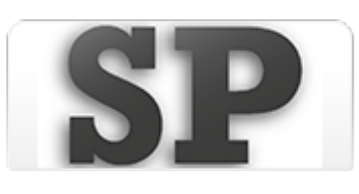

Sociedades precapitalistas

ISSN: 2250-5121

publicaciones@fahce.unlp.edu.ar

Universidad Nacional de La Plata

Argentina

\title{
“...tierras de labranza por rentas moderadas [georgías epi metríais misthóses]" (Isoc. 7.32). Explotación y relaciones de trabajo rural entre los ciudadanos atenienses durante la democracia
}

\author{
Paiaro, Diego \\ "...tierras de labranza por rentas moderadas [georgías epì metríais misthósesi]" (Isoc. 7.32). Explotación \\ y relaciones de trabajo rural entre los ciudadanos atenienses durante la democracia \\ Sociedades precapitalistas, núm. 10, 2020 \\ Universidad Nacional de La Plata, Argentina \\ DOI: https://doi.org/10.24215/22505121e043
}

Atribución no comercial compartir igual (CC BY-NC-SA) 4.0 
Dossier: Formas de explotación del trabajo y relaciones laborales en sociedades preindustriales "...tierras de labranza por rentas moderadas [georgías epi metríais misthósesi]" (Isoc. 7.32). Explotación y relaciones de trabajo rural entre los ciudadanos atenienses durante la democracia

“...lands at moderate rentals [georgias epi metriais misthosesi]" (Isoc. 7.32). Exploitation and rural labour relations between Athenian citizens during the democracy

Diego Paiaro

DOI: https://doi.org/10.24215/22505121e043

Universidad Nacional de General Sarmiento / Universidad

de Buenos Aires / Programa PEFSCEA / Instituto

de Historia Antigua y Medieval "Prof. José Luis

Romero" (FFyL-UBA), CONICET, Argentina

diegopaiaro@hotmail.com

Recepción: 23 Mayo 2019

Aprobación: 27 Junio 2019

Recepción: 23 Mayo 2019

Aprobación: 27 Junio 2019

\section{Resumen:}

Partiendo de la propuesta de Isócrates de volver a tiempos en los que los ricos cedían tierras a los pobres por rentas moderadas, en el presente trabajo se analizan las relaciones de misthosis en el contexto de la democracia ateniense. En primer lugar se consideran las características estructurales que enmarcaban este tipo de relación social y que atañen a la distribución de la tierra y las condiciones de acceso a las mismas. En segundo lugar se analiza diverso tipo de evidencia que permite reconstruir algunas de las características principales de la práctica del arriendo de tierras entre ciudadanos. En base al análisis de fuentes se propone que, por un lado, en oposición a la perspectiva desarrollada por varios especialistas, las relaciones de misthosis se encontraban bastante más desarrolladas de lo que suele pensarse dado lo exiguo del material documental. Por otro lado, se modera la idea de que el arriendo de tierras constituyó un mecanismo importante de explotación en manos de los ciudadanos ricos, particularmente útil en un siglo IV a.C. concebido como de pauperización del campesinado. Por último, se analizan las necesidades tanto de los terratenientes como de los productores directos que eran suplidas a través de relaciones de tenencia.

Palabras clave: Atenas, Democracia , Agricultura , Explotación, Trabajo , misthosis.

\section{Abstract:}

The proposal made by Isocrates about returning to the good old times in which the rich yielded land to the poor at moderate rentals, is taken as a starting point in order to analyze the misthosis relationships in the context of Athenian democracy. In the first place, the structural characteristics that frame this type of social relationship (concerning the distribution of the land and its conditions of access) are considered. Secondly, evidence is analyzed in order to reconstruct some of the main characteristics of land leases between citizens. Based on the analysis of sources, it is proposed that, on the one hand, in opposition to the perspective developed by several specialists, misthosis relationships were much more developed than is usually thought given the limited amount of documentary material. On the other hand, the idea that the lease of land was an important mechanism of exploitation in the hands of rich citizens (particularly useful in a fourth century BC conceived as one of pauperization of the peasantry) is moderated. Finally, the needs of both the landowners and the direct producers that were supplied through tenure relations are analyzed.

KeYwords: Athens, Democracy, Agriculture, Exploitation , Labour, Místhosis.

\section{El PASAdo SIEMPRE FUE MEJor (PARA Isócrates)}

Isócrates, autor de la frase que titula este trabajo, fue uno de los más importantes retóricos de Atenas durante el período que va desde el fin de la guerra con Esparta hasta el ascenso de Macedonia. Hacia finales del siglo $\mathrm{V}$ a.C. y a su propio pesar (15.161-2) había comenzado a desarrollar la profesión de logógrafo a partir del hecho de que durante la Guerra del Peloponeso su familia había "perdido todos nuestros bienes" con los que su padre había sido "útil a la ciudad y al mismo tiempo" capaz de dar a sus hijos una "cuidadosa educación". 
Desde la década del 390 a.C. abandonó dicha profesión para volcarse a la enseñanza y la escritura de textos que, a pesar de tener la forma de discursos, no tenían como objetivo su enunciación en los espacios públicos e institucionales propios de la palabra política sino, más bien, su circulación en forma escrita. Estas actividades le habrían permitido recobrar cierta fortuna ya que sabemos que Isócrates fue integrado en la clase litúrgica ateniense $(15.145)^{1}$, es decir, dentro del grupo de los 1.200 ciudadanos más acaudalados sobre los que la ciudad imponía una serie de contribuciones económicas (leitourgía) con el objeto solventar determinados gastos (Mirhady \& Too, 2000, p. 1-11).

Se trata de un autor que, políticamente, algunos especialistas han asociado a Terámenes (Canfora, 1990) -figura ciertamente ambigua y cuya valoración cambia entre los siglos V y IV a.C., cf. Harding (1974), Sancho Rocher (2016)-, es decir, con posturas oligárquicas que podrían ser calificadas como "moderadas". Tales tendencias "moderadas", pero que creemos se definen mejor como "criptooligárquicas", habrían tenido su continuidad en el siglo IV a.C. bajo la forma de una defensa de aquello que culminó por denominarse como la "constitución ancestral" (pátrios politeía) ${ }^{2}$. Ahora bien, el pequeño fragmento de cita con el que titulamos este artículo proviene de un discurso conocido como Aeropagitico que fue fechado para mediados del siglo IV a.C. (ca. 358-2 a.C.) de acuerdo con la crítica especializada (Mirhady \& Too, 2000, p. 182). En el mencionado discurso, Isócrates expresa descontento con el régimen político vigente Atenas y, a la vez, propone la necesidad de "regresar" a la pátrios politeía que, ya para esa época, constituía una construcción tópica plenamente consolidada y principal eje en torno del cual se nucleaban las propuestas críticas a la demokratía. De esa manera, para la perspectiva del orador, Atenas podría superar sus problemas y recobrar la supremacía de antaño. La solución consistía en "recobrar aquella democracia que Solón, el mayor demócrata [ho demotikótatos], nos legisló y Clístenes reestableció tras expulsar a los tiranos y traer de nuevo al pueblo" (7.16). Así, para Isócrates (7.60) su opinión es fácil de conocer puesto que en sus discursos siempre ha criticado "a las oligarquías y los privilegios [oligarkhiais kai taîs pleonexíasis epitimôn]" y alabado a los regímenes "igualitarios y las democracias [isótetas kai tás demokratías]" pero "no a todas, sino a las bien establecidas [kalôs kathestekuias]", las que poseen "justicia [dikaios]" y "razón [lógon]". Inmediatamente el orador afirma saber "que nuestros antepasados con esta constitución se distinguieron mucho de los demás y que los lacedemonios están muy bien gobernados [kállista politeuoménos] porque gozan de una gran democracia [málista demokratoúmenoi]" $(6.61)^{3}$. En una misma frase, Isócrates muestra los dos principales fundamentos de los críticos de la democracia vigente en Atenas: la reivindicación de la pátrios politeía y el filolaconismo ${ }^{4}$.

Pero, más allá de esta postura crítica de Isócrates con respecto a la demokratía (Requena, 2013a; cf. Sancho Rocher, 2008), citaremos un fragmento del discurso para ver cómo este posicionamiento político se entrelaza con la problemática de la que nos ocuparemos en este escrito, es decir, de un determinado tipo de relaciones socioproductivas entre los ciudadanos del mundo rural ático. Así, describiendo aquella democracia de Solón que debía ser recobrada, Isócrates afirmaba que:

\footnotetext{
"Los ciudadanos más pobres [hoí penésteroi tôn politôn] estaban tan lejos de envidiar a los más hacendados, [...], por pensar que la felicidad de aquéllos les procuraba bienestar. Quienes tenían haciendas no menospreciaban a los que se hallaban en una situación más menesterosa, sino consideraban que era para ellos una vergüenza la pobreza de los ciudadanos [tèn tôn politôn aporian] y socorrían sus necesidades, confiando a unos tierras de labranza por moderadas rentas [georgias epi metriais misthósesi], mandando a otros a comerciar y suministrando a algunos capitales para otros trabajos. [...] Los que eran más pobres se dedicaban a la agricultura y el comercio, por saber que la pobreza [aporias] se produce por la pereza y la maldad por la pobreza [aporias] [...]. [La democracia ancestral]... liberó a los pobres [toùs pénetas] de sus miserias [tôn aporiôn] mediante el trabajo y la ayuda de los ricos" $(7.31-3,44,55)^{5}$.
}

Como podemos ver, Isócrates presentaba el (imaginario) panorama social vigente durante la pátriospoliteía como uno en el que los sectores acaudalados de la ciudadanía ponían en práctica diversos mecanismos para evitar la miseria de los ciudadanos más pobres. Como afirma Plácido (2008, p. 231), esta forma de presentar el pasado buscaba "sustituir el misthós político como pago por funciones públicas por el misthós como renta de 
trabajo, como el practicado en las explotaciones agrarias del arcaísmo, según Isócrates". En una alocución en la que aparecen más los temas ideológicos de mediados del siglo IV a.C. que las realidades agrarias de la Atenas del siglo VI a.C. (Plácido, 1997, p. 286; Wood, 1988, p. 97-8), en definitiva de lo que se trataba era de excluir al dêmos pobre del poder al que había accedido bajo la demokratía con el objetivo de reintroducir en la pólis formas tradicionales patronazgo y dependencia ${ }^{6}$. En particular, lo que nos interesa de la propuesta isocrática es el hecho de que en ella aparece una referencia a un pasado en el predominaba en el mundo rural la concesión de tierras de labranza (georgías) a cambio de rentas (misthosis) que serían moderadas (metrías) como relación socioproductiva que implicaba a los ciudadanos ricos con los pobres. La intervención de Isócrates y su propuesta de modificar - mirando a un pasado ciertamente más imaginario que real- las relaciones de trabajo vigentes en su propio tiempo en los campos del Ática nos sitúa frente una serie de temáticas que tratemos en lo que resta: ¿cuáles eran las condiciones estructurales a partir de las cuales se enmarcaba la concesión de tierras de labranza a cambio de rentas entre los ciudadanos de Atenas?; ¿se trataba de una práctica habitual como modo de explotación de la tierra agrícola?; ¿qué tipo de vínculo se daba entre aquellos ciudadanos que trabajaban la tierra y aquellos que percibían las rentas?; la propuesta de Isócrates, ¿indica que en su tiempo las rentas eran demasiado elevadas, es decir, habían dejado de ser "moderadas" (métrios) y, por ende, su propuesta estaba orientada a una reducción generalizada de la renta (misthosis)?; o, por el contrario, ¿el orador escribía en un contexto en el cual ese tipo de relación productiva había dejado de ser significativa y, entonces, su propuesta era (re)generarla en su propia contemporaneidad? En fin, se trata de una serie de cuestiones encadenadas y, como punto de partida, lo mejor será empezar por comprender el marco general y las constricciones estructurales que organizaban el desarrollo de este tipo de relación socioproductiva.

\section{Tierras de labranza a Cambio de rentas (místhosis) en el marco de la CiUdAD DEMOCRÁTICA}

Como punto de partida para entender las características de la cesión de tierras de labranza a cambio de rentas (misthosis $)^{7}$ entre los ciudadanos de la que hablaba Isócrates, creemos que resulta necesario tomar en cuenta algunos elementos que constituyen el marco a partir del cual este tipo de relación social de producción se desarrollaba ${ }^{8}$. En términos generales, podemos decir que el arrendamiento de tierras constituye un tipo de vínculo productivo que cubre un amplio y variado espectro de situaciones concretas. De acuerdo con Kehoe (2012, p. 1), "Farm tenancy, involving one person cultivating the land belonging to another in exchange for some kind of payment, was a basic institution in the ancient economy, as it is in virtually all preindustrial agrarian economies" (cf. MacDowell, 1978, p. 140-2).

De este modo, un primer aspecto a tener en cuenta es la existencia de un determinado nivel de desigualdad en la distribución de la tierra agrícola. Tal desigualdad implicaría que, por un lado, algunos ciudadanos dispusieran de más tierras de las que podían explotar directamente a partir de su propio trabajo y de la mano de obra familiar; en tanto, por otro lado, otro grupo de ciudadanos tendrían menos tierras (o no tendrían tierras en absoluto) que las necesarias para asegurar la reproducción de su unidad doméstica. Lo anterior, habría supuesto para estos últimos la necesidad estructural de acceder a lotes agrícolas (u otro tipo de ingresos) para cubrir sus necesidades y garantizar su subsistencia. En este sentido, entonces, se puede afirmar que el reparto inequitativo de la tierra de labranza constituye un elemento estructuralmente necesario para el desarrollo de relaciones de arrendamiento entre lo que podríamos definir como los campesinos ${ }^{9}$ y los terratenientes ${ }^{10}$ del Ática. Si bien el análisis de la distribución de la tierra agrícola es un problema complejo que requiere de un tratamiento extenso (y que no podemos abordar aquí), creemos bastante seguro afirmar, basándonos en estudios específicos sobre el tema, que la Atenas de los siglos V y IV a.C. conoció un reparto inequitativo de la tierra que justifica plenamente la indagación sobre las prácticas de arrendamientos ${ }^{11}$. 
El segundo de los aspectos que enmarcan la problemática tiene que ver con las condiciones a partir de las cuales los agricultores accedían a la tierra. Particularmente en las sociedades precapitalistas, el hecho de que existan múltiples formas condicionales de posesión (y que no siempre se pueda distinguir taxativamente entre los propietarios y los no propietarios) determina que las relaciones entre terratenientes y arrendatarios sean muy variadas dependiendo, a la vez, de factores tales como la demografía, el régimen agrario, la disponibilidad de tierras, etc. En este sentido, la stásis de la época arcaica y las reformas de Solón a las que dio lugar constituyen un hito central de la historia rural ateniense. Luego de la actuación del legislador y gracias a las transformaciones político-jurídicas por este impulsadas, los campesinos del Ática comenzaron a gozar de seguridad en la posesión de sus lotes agrícolas (klêroi) y, conjuntamente, derechos a la participación política que se fueron ampliando y que los protegieron de la explotación por parte de los terratenientes. Así, la integración de los productores directos en el plano institucional de la pólis operó contra el desarrollo de formas regulares y sistemáticas de transferencia de excedentes (por mecanismos comúnmente denominados "extraeconómicos") desde las unidades de producción campesina hacia los terratenientes y/o el Estado ${ }^{12}$. Más allá de que la cuestión de la propiedad (privada) de la tierra haya tenido sus complejidades para el caso ateniense ${ }^{13}$, lo cierto es que los ciudadanos tuvieron políticamente asegurado el acceso a ella y este no dependía de la subordinación del productor directo a los terratenientes o al Estado como sucede, por ejemplo, en las sociedades feudales o tributarias. En definitiva, bajo la "forma de propiedad antigua" (Marx, 1989, p. 72), el acceso al klêros por parte del ciudadano dependía exclusivamente de (el mantenimiento de) su pertenencia a la comunidad cívica encontrándose, de esa manera, libre de vínculos de dependencia. Por ende, la ambigüedad que el concepto de propiedad tenía en el mundo griego no nos permite derivar de ello un argumento a favor de la existencia de relaciones de arrendamiento o aparcería (contra Wood, 1988, p. 75). El hecho de que no se haya desarrollado una definición nítida de propiedad privada no implicó, en Atenas, que el acceso a la tierra estuviera mediado por alguna condicionalidad para los miembros de la comunidad siempre y cuando estos pudieran mantener su pertenencia al cuerpo cívico.

En síntesis, podemos decir que las relaciones de arrendamiento en el Ática no se desarrollaron sobre una diferencia política, jurídica o estamental entre el terrateniente y el productor. A la vez, tampoco se dieron como consecuencia de un acceso condicional a la tierra a causa de la ausencia de propiedad absoluta del medio de producción; es decir, no estuvieron enmarcadas en relaciones de compulsión extraeconómica ${ }^{14}$. Por el contrario, la única base para el desarrollo de arrendamientos la constituye la distribución desigual de la tierra entre los miembros de la comunidad ${ }^{15}$. En definitiva, estimamos que el desarrollo conjunto de una igualación radical de los ciudadanos en el plano político e institucional junto con cierto grado de desigualdad en la distribución de la tierra, justifican la pesquisa acerca de la existencia de mecanismos menos formales y estables ("económicos"16) que unían a los productores directos y los terratenientes del Ática; el arriendo de tierras constituiría uno de ellos.

\section{Del “neXt to nothing” De Finley a las EVidencias (nO tan) indirectas}

Ahora bien, una vez enmarcada la problemática, es necesario proceder al análisis de la documentación que nos permite reconstruir este tipo de relación productiva. Las lagunas documentales constituyen, en este sentido, el más importante escollo con el que se han topado los investigadores al momento de analizar las relaciones de arrendamiento privado durante la democracia. Se debe decir que, sin embargo, la situación es bastante contrastante cuando se la compara con el caso de los arriendos de tierras "públicas" o, mejor aún, pertenecientes a alguna entidad colectiva -como ser la propia ciudad (pólis), los demos del Ática, las fratrías, las tribus, los agrupamientos religiosos, etc.- en tanto para esos casos subsiste una buena dotación de material documental de carácter epigráfico que ha permitido desarrollar estudios especializados ${ }^{17}$. Es ese contraste el que ha llevado a Finley (1985, p. 216 n. 68) a afirmar que "we know next to nothing about the leasing of land 
owned by individuals in Athens. The agreements were not engraved in stone”. Este escenario es responsable, creemos nosotros, de que las relaciones de arrendamiento sobre tierras privadas no hayan recibido de manera frecuente un tratamiento sistemático por parte de los especialistas ${ }^{18}$. En términos generales, debemos decir que las fuentes con la que contamos son escasas, en muchos casos, ambiguas y, relativamente, acotadas en el tiempo ya que se debe esperar a finales del siglo $\mathrm{V}$ a.C. para que comiencen a aparecer algunas (pocas) referencias documentales (Osborne, 1988, p. 304; Burford, 1993, p. 178; Jones, 2004, p. 27; Foxhall, 2007, p. 75).

Ahora bien, la propia escasez de documentos ha sido utilizada por algunos investigadores como evidencia positiva para afirmar la poca importancia que este tipo de relación productiva tenía en la Atenas democrática. Es decir, ante la carestía de documentos, se infiere la poca relevancia de la práctica. Así, para Zimmern (1961, p. 234) las relaciones de tenencia eran "practically unknown in Greece" puesto que de las múltiples inscripciones preservadas, "there are only a very small number of contracts made between individuals". En función de esta particular conservación de documentos ser concluye que "when a Greek is a tenant at all he is a tenant for a public body". En el mismo sentido Mossé (1980, p. 82) afirma que "el arrendatario [era] un fenómeno poco extendido en la Atenas clásica (si exceptuamos las tierras de los templos y los bienes pertenecientes a los niños, que eran arrendados por sus tutores)". Finalmente, para Foxhall (2007, p. 75) "almost no evidence for private tenancy exists in classical Athens [...]...for the fragmented holdings of wealthy households it seems more likely that scattered plots were worked by slaves".

Basándose en una lógica parecida, otros investigadores han planteado que el hecho de que subsista una mayor proporción de evidencia para el siglo IV a.C. que para su antecesor, puede ser explicado vinculando el fenómeno del arriendo con los cambios que habrían acontecido hacia el final (y, en parte, como consecuencia) de la Guerra del Peloponeso. Desde estas perspectivas, el inicio del siglo IV a.C. daría paso a un período caracterizado como la "crisis de la ciudad-estado" ${ }^{19}$ o, incluso, de decadencia del "ideal del ciudadanocampesino" ${ }^{20}$ en el que la tierra se mercantilizó y concentró produciendo una tendencia a la pauperización y caída en dependencia de los pequeños y medianos agricultores. Desde esta perspectiva, recientemente, Valdés Guía (2015, p. 183) ha argumentado que luego de perder la guerra y su Imperio, Atenas conoció un período signado por una "pobreza generalizada" del dêmos y una "clara polarización entre ricos y pobres". Esta situación habría llevado, de acuerdo a la autora, a que una parte importante del dêmos se haya visto obligada a trabajar por un misthós (salario) y a caer en distintas situaciones de dependencia económica y social (cf. Plácido, 2008; Valdés Guía, 2018, p. 109-16), entre ellas, el arriendo de lotes agrícolas "en situaciones desfavorables para los que arrendaban la propiedad”, generalmente, pobres con poca o ninguna tierra (p. 188). Por ende, la documentación sobre arriendos entre ciudadanos del siglo IV a.C. se vincularía a la (supuesta) pauperización de los agricultores y su caída en dependencia en contraste con las características del siglo precedente. En definitiva, la pobreza habría forzado a los labradores a someterse a relaciones de tenencia consideradas como desfavorables para estos, asimiladas a la dependencia; en última instancia, se trataría de un mecanismo de explotación en mano de los ciudadanos ricos para someter a los pobres.

Sin embargo, plantearemos en lo que sigue ver a la misthosis y a la documentación conservada acerca de ella bajo otra perspectiva. En primer lugar, propondremos revisar el supuesto carácter explotativo de esta relación social por un modelo que tome en cuenta las necesidades tanto de los terratenientes como de los arrendatarios. En cuanto a la documentación, creemos que debe ser tomado en serio aquello que han argumentado algunos especialistas: la parte sustancial de la evidencia puede simplemente haber desaparecido y, en todo caso, es necesario considerar que la escritura de cualquier transacción legal era bastante rara antes de mediados del siglo IV a.C. ${ }^{21}$ en tanto los acuerdos verbales frente a testigos eran considerados mecanismos mucho más confiables (Osborne, 1988, p. 304 y 306; Burford, 1993, p. 180). En función de esto y para avanzar, creemos justificado pasar del "next to nothing" de Finley a las evidencias (en algunos casos) indirectas sobre relaciones de misthosis entre ciudadanos. 
En primer lugar, creemos importante insistir sobre la regularidad de la práctica que atestiguan -en muchas ocasiones de modo tangencial- los documentos. Un estela procedente de la Acrópolis (Meiggs \& Lewis, 1988, p. 25-7) y datada por los especialistas para finales del siglo VI a.C. (508-500 a.C.) contiene un decreto sobre los clerucos atenienses en Salamina ( IG I $^{3}$ 1), posiblemente la primera de las cleruquías establecida por Atenas (Moreno, 2007, p. 102; Zuchtriegel, 2018, p. 16-24). Si bien fragmentaria, la inscripción nos informa claramente acerca de la prohibición decretada por el dêmos contra la posibilidad de que aquellos atenienses que habían recibido asignaciones de tierra en la isla las arrienden:

"The People decided: (those who hold an allotment) at Salamis / shall be permitted to (?) reside on Salamis ... at (Athens) / they shall pay taxes and do military service; their (property at Salamis) / they shall not lease [mé misthôn], if not ... ; but if / anyone leases [misthôi], fined (shall be the tenant [tó misthómenon] and the) / landlord [misthônta], each of them ... to the public treasury..."22.

Posiblemente el decreto tenía como objetivo principal el de asegurar la presencia de los clerucos en la isla (y evitar la figura del terrateniente absentista) como un mecanismo de control del territorio pero lo que para nosotros constituye un elemento a ser considerado es el hecho de que expresamente prohibía la posibilidad de que aquellas tierras que habían sido asignadas fueran puestas bajo relaciones de misthosis. Si bien no de modo directo, creemos que esta mención explícita a la práctica podría estar en el Ática (Davies, 1981, p. 49 n. 22). Así, el decreto se puede entender como un intento del dêmos de evitar que una práctica común o al menos conocida se traslade al contexto de la cleruquía en la que la presencia del ciudadano en la tierra resultaba estratégicamente fundamental para su defensa.

Por otro lado, continuando con el control de territorios más allá del Ática, resulta interesante un fragmento de Tucídides acerca de las acciones que emprendió Atenas como represalia a la revuelta de los lesbios (427 a.C.). Aquí, el pago de la renta aparece claramente mediado por el uso de la coerción, es decir, funciona bajo un registro propio de la dominación militar y, por ende, ajeno a las relaciones entre ciudadanos:

"Después de esto [los atenienses] no fijaron un tributo [phóron] a los lesbios, sino que, tras dividir la tierra (...) en tres mil lotes [klérous], reservaron trescientos para consagrarlos a los dioses, y a los otros enviaron clerucos sacados a suerte [kleroúkhous toìs lakbóntas] entre ellos [ciudadanos atenienses]; con éstos, los lesbios se comprometieron a pagar una suma de dos minas al año por cada lote, y ellos mismos siguieron trabajando la tierra [autoi eirgázonto tèn gên]...” (Thuc. 3.50.2-3) ${ }^{23}$.

Analizando otros caos sobre la relación entre Atenas y las poblaciones dependientes de su Imperio, ZelnickAbramovitz (2004, p. 330-42) llegaba a la conclusión de que existió un patrón común de explotación sobre los habitantes locales por los colonos atenienses y que hombres libres que poseían la tierra habían sido transformados sujetos "dependent for their living on foreign settlers and lessors" (p. 342). En síntesis, el arriendo de tierras a cambio de rentas parece haber sido una práctica común en tanto forma de relación social entre los clerucos atenienses y las poblaciones sometidas a la arkhé de Atenas. Sin embargo, se debe destacar que se trataría de una situación diferente a la presente en el Ática puesto que en la experiencia del Imperio se vio alterada una de las condiciones que, como vimos en el apartado anterior, constituían el marco estructural de las relaciones de tenencia entre ciudadanos. Si el ciudadano ateniense accedía a la tierra de labranza en el Ática solo a condición de mantenerse como miembro de la comunidad política, el arrendatario de las cleruquías lo hacía bajo una condicionalidad marcada por la dependencia del dominio imperial. Es en este sentido que, creemos, se debe entender la característica explotativa -mediatizada por vínculos de coerción extraeconómica- que Zelnick-Abramovitz atribuye a las relaciones entre atenienses y arrendatarios locales.

Pero junto a esta evidencia procedente del Imperio, y habiendo ya tratado el caso de Isócrates (7.32), corresponde ahora posar la mirada sobre una serie de evidencias que nos permiten considerar que las relaciones de tenencia fueron -como lo ha propuesto Osborne (1988, p. 311)- un tipo de vínculo productivo entre terratenientes y campesinos que para la época clásica era conocido, común y continuado en el Ática desde el arcaísmo (Wood, 1988, p. 181-2). Es cierto que se trata de documentos en los que la misthosis aparece de modo colateral, accesorio, secundario, etc. Tal es el caso de un discurso de Lisias confeccionado para la 
defensa de un propietario de tierras que, hacia principios del siglo IV a.C., fue juzgado por el Areópago por un crimen vinculado a los olivos sagrados asociados a la diosa Atenea (Isager \& Skydsgaard, 1992, p. 203-5; Millett, 2002, p. 31-2; Foxhall, 2007, p. 117-21); Papazarkadas, 2011, p. 260-84) acontecido en el año 397/6 a.C., durante el arcontado de Suníades (Lys. 7.11). El discurso buscaba argumentar que en el lote de tierra en cuestión, nunca hubo olivos sagrados y, al hacerlo, realiza un racconto de cómo la propiedad fue cultivada a través del tiempo; es allí que aparecen menciones al arriendo:

\begin{abstract}
"Esta tierra pertenecía a Pisandro. Cuando los bienes de éste fueron confiscados [demeuthénton], Apolodoro de Mégara los recibió coma regalo(...). Poco antes de los Treinta se la compró Anticles y la arrendó [exemisthosen]. Yo se la compré [onoûmai] a Anticles cuando se hizo la paz [...]....cuando yo entré en posesión de la finca, antes de que pasaran cinco días, se la arrendé [apemisthosa] a Calístrato con Pitodoro de arconte. Éste la cultivó [egeórgesen] durante dos años sin que recibiera ningún olivo ni privado ni sagrado ni tocón alguno. Al tercer año la cultivó [eirgásato] Demetrio, aquí presente. El cuarto año se la cedí en arrendamiento [emisthosa] a Alcias, liberto de Antístenes, que ha fallecido. Después, durante tres años, la cultivó igualmente en arrendamiento [emisthósato] Proteas [...]. Cuando había transcurrido este tiempo, la cultivé yo mismo [autòs georgô]. El acusador afirma que, con Suníades de arconte, yo arranqué un tocón. Pero los que la cultivaron antes [hoi próteron ergazómenoi] y los muchos que la tuvieron de mí en arrendamiento [pollà éte gar'emồ memisthoménoi] muchos años, os han testificado que no había ningún tocón en la finca” (Lys. 7.4, 9-11).
\end{abstract}

Varios aspectos importantes de desprenden del texto. En primer lugar se debe decir que se trata de un lote de tierra privada que luego de haber sido confiscada circuló a través del proceso de compra y venta entre diversos propietarios. Por otro lado, se constata que diferentes términos y formulaciones hacen referencia a misthosis para dar cuenta del hecho de que la tierra fue cedida en arriendo por parte del propietario. Del discurso no se desprende ningún indicio que nos permita pensar que los acuerdos de tenencia eran puestos por escrito y, más aún, el hecho de que se marque la presencia de Demetrio en el juicio es un claro índice de la importancia de los testigos para este tipo de acuerdos en contextos forenses. En el discurso aparecen cuatro colonos sucesivos que usufructuaron el lote durante un total de siete años: el primero por dos años, otros dos arrendatarios por un año cada uno y el último durante tres años. Se debe destacar el hecho de que tanto Anticles como el cliente de Lisias no parecieran haber tenido problemas a la hora de encontrar un arrendatario incluso en un período de dificultades como lo fue el inmediatamente posterior al fin de la Guerra del Peloponeso ${ }^{24}$. En síntesis, el discurso nos sitúa frente a un terrateniente rico (capaz de contratar a un importante logógrafo para su defensa $)^{25}$ propietario de una serie de pequeñas o medianas parcelas diseminadas por el Ática que eran trabajadas tanto por esclavos como también por arrendatarios que debían entregar a cambio una determinada renta. Nada en el documento parece indicar que este tipo de práctica era poco habitual, más bien, el hecho de que un propietario anterior (Anticles) haya explotado el lote también bajo el régimen de arriendo permitiría argumentar en el sentido contrario (Wood, 1988, p. 73; Burford, 1993, p. 178; McHugh, 2017, p. 40-1) ${ }^{26}$. Por último, el hecho de que uno de los colonos sea un liberto (Alcias) indicaría que el arriendo de tierras a no ciudadanos era un práctica, al menos, conocida y no demasiado excepcional dado que en el discurso no parece haber necesidad de una argumentación específica sobre el tema ${ }^{27}$.

En otro discurso de Lisias, conocido como Sobre los bienes de Eratón: contra el tesoro (Lys. 17) y fechado por la crítica hacia mediados de la década de 390 a.C. (Todd, 2000, p. 185), aparecen también algunas evidencias de modo colateral. Esta pieza forense fue confeccionada para reclamar al Tesoro de la ciudad una parte de una propiedad que había sido confiscada. El caso se puede reconstruir de la siguiente manera: el abuelo del demandante había prestado dos talentos a Eratón quien pagó regularmente los intereses hasta su muerte acaecida en torno a la guerra del Peloponeso; luego, los tres hijos del deudor (Eratón II, Erasifonte y Erasístrato) dejaron de pagar al acreedor y el padre del demandante acusó a Erasístrato obteniendo su condena. Finalmente, la ciudad terminó por confiscar todos los bienes de Eratón y, frente a ello, el demandante llevó a cabo el proceso que suscitó este discurso lisíaco. Pero, más allá de las características y particularidades del proceso, lo que interesa en relación al tema que estamos tratando es el hecho de que el 
orador, con el objetivo de dejar en claro que al momento de ser confiscadas por la pólis las tierras en cuestión se encontraban bajo su propiedad, argumenta que:

"Durante todo el tiempo que los familiares de Erasifonte nos disputaron estos bienes, yo los reclamaba todos como míos (...). Las propiedades de Esfeto las tengo arrendadas [emisthoka] desde hace tres años, mientras que por las de Cicinna y por la casa he estado litigando con sus ocupantes. [...] Pues bien, para que veáis que ello es verdad, os presentaré como testigos [márturas], primero, a los que me tienen arrendada [memisthoménous] la finca de Esfeto” (Lys. 17.5, 8).

Los fragmentos citados presentan una serie de elementos que son útiles para reflexionar. Del mismo modo que en el discurso que analizamos previamente, en este el arriendo de tierras aparece como una forma para nada excepcional de explotar la tierra (referido, también, con términos dependientes de misthosis). Asimismo, tampoco en este discurso se hace referencia a un contrato escrito y son los testimonios de los colonos los utilizados como elemento de prueba frente al tribunal. Resulta probable que el uso del plural para introducir a los testimonios que se van a presentar (márturas) esté dando cuenta del hecho de que las tierras que el demandante poseía en el demo de Esfeto eran arrendadas a más de un colono. En este sentido se abren una serie de posibilidades, a saber: puede ser que se trate de diferentes colonos que, de forma sucesiva, arrendaron el mismo lote; otra posibilidad es que un único lote haya sido dividido y puesto en arriendo con diferentes tenentes; o bien, por último, se trataba de una propiedad dispersa en diferentes parcelas que eran arrendadas de manera independiente por el propietario (Osborne, 1988, p. 314 opta por la segunda de las opciones). Pero, más allá de las diferentes alternativas (sobre las que no tenemos casi elementos para privilegiar a una por sobre las otras), lo cierto es que el arriendo se presenta como un mecanismo común de administración de la tierra.

En síntesis, a pesar de los límites planteados por la documentación, en esta sección hemos podido constatar que las relaciones estructuradas a partir de la cesión de tierras a cambio de rentas constituía un tipo de vínculo socioproductivo que resultaba común y continuado en el tiempo en la agricultura ática de los siglos V y IV a.C. En lo que sigue trabajaremos sobre qué tipo de lógicas operaban por detrás de las relaciones de tenencia.

\section{LA LÓGICA DE LA MÍsthosis}

En primer lugar, creemos importante señalar que en los dos casos presentados en los discursos de Lisias, las tierras que fueron puestas en arriendo no pertenecían a lo que se denominaba la "propiedad ancestral", es decir, aquellas tierras que se consideraba que habían permanecido en manos de la misma familia a lo largo de generaciones y en las que se encontraban enterrados los ancestros (Burford, 1993, p. 97). En contraste, los lotes agrícolas que aparecen en los discursos llegan a mano de sus propietarios a través de la compra-venta en uno de los casos y como resultado de una disputa judicial en el otro. El dato resulta de interés para comprender el modo en el que la élite ateniense accedía y administraba sus bienes.

Una parte nada despreciable de la evidencia con la que contamos para el arriendo de tierras en el Ática -y con seguridad la más importante en el aspecto cuantitativo- proviene de las listas de propiedades de varias familias ricas atenienses que han subsistido hasta nuestra época y que recibieron un análisis detallado y específico por parte de Davies (1981). En base al trabajo de Davis (1981, p. 127, 202, 335, 553, 589-90), Osborne (1988, p. 311-4) sistematizó los datos comprobando que en seis de las listas de propiedades aparece mencionado el arriendo de forma explícita, en dos se asume implícitamente y en los cinco casos restantes, si bien es cierto que parecen no estar presentes, se debe tener en cuenta que se trata de casos que resultan algo problemáticos (p.e. el de Lisias que al no ser de una familia ciudadana no podía ser propietario de lotes agrícolas). Ahora bien, más allá de que estos datos no permiten decir que el arriendo de tierras fue la práctica que dominaba el panorama de las familias acaudaladas (en ningún caso se arrendaron todas las propiedades), resulta importante el hecho de que al menos una parte de las tierras se arrendaban con cierta regularidad. De 
acuerdo con Davies (1981, p. 49), "rents from houses and farmland appear as a common constituent of the income a man of any substance".

Lo anterior nos sitúa, entonces, frente a la problemática de cómo administraban sus propiedades las familias acaudaladas. De modo algo esquemático, se puede decir que los terratenientes atenienses disponían de tres alternativas al momento de gestionar su tierras: por un lado, el propietario podía explotar directamente la tierra junto con su familia; por otro lado, podía dejar la gestión de la hacienda en manos de un administrador (mayormente un liberto o un esclavo); y, finalmente, podía arrendar su propiedad a cambio de rentas (cf. Burford, 1993, p. 117; Carlsen, 2002, p. 117). Dado este marco, no resulta extraño, entonces, el hecho de que el arriendo de una parte de la propiedad se haya encontrado como estrategia en la mayoría de los ciudadanos ricos para los que contamos con datos sustanciales. La fragmentación y dispersión a lo largo del Ática que caracterizaba las haciendas de los grandes propietarios (Osborne, 1985, p. 62-3; 1987, p. 37-40; Burford 1993, p. 110-1, 119; Isager \& Skydsgaard 1991, p. 128; Carlsen, 2002, p. 123; Foxhall, 2007, p. 56-8) posiblemente haya dificultado y hecho onerosa la supervisión directa de las mismas. Dada esta característica, la cesión en arriendo a familias campesinas puede haber consistido la alternativa más razonable para los terratenientes en tanto evitaba los riesgos y los costos que la explotación directa o a través de administradores traía aparejados. El arriendo habría permitido a los propietarios evitar la necesidad de, o bien, disponer de tiempo libre para trasladarse a distintas zonas del Ática y controlar tanto las condiciones locales como a la mano de obra ${ }^{28}$; o bien, disponer de dinero para contratar o comprar a alguien encargado de la supervisión de lotes agrícolas que, siendo de relativamente pequeño tamaño, requerían una baja dotación de mano de obra (cf. Wood, 1988, p. 73; 2002, p. 19-20) lo cual hacía del control algo bastante oneroso. Frente a este panorama (parcelas de pequeña dimensión, dispersas, asiladas unas de otras y alejadas), se puede estimar que el arriendo a familias de labradores haya sido una alternativa bastante común para los terratenientes tanto para garantizarse un ingreso a partir de la renta como, por analogía con lo que aparece en los contratos de arriendo sobre tierras públicas, para mantener la capacidad de producción de sus lotes (cf. Jameson, 1982; Burford, 1993, p. 180-1).

Por otro lado, la percepción de rentas seguramente constituyó una fuente regular de ingreso de dinero para los hacendados a pesar de que su valoración cuantitativa y proporcional con respecto al resto de sus ingresos nos es imposible de ser estimada. Un modo de pensar la posible función que esa renta habría tenido es a partir de la importancia que el dinero ocupaba en el modo de vida de los ciudadanos acaudalados (Plu. Per. 16). Al respecto, Osborne (2003) ha analizado la necesidad que los ciudadanos más ricos tenían de contar con un ingreso regular de dinero en efectivo. Las propiedades de Fenipo y de su oponente Demóstenes ([D.] 42), permitieron al autor destacar la preferencia que los miembros de la clase litúrgica tenían por "empresas de alto rendimiento en efectivo" (Osborne, 2003, p. 194). Esta necesidad de ingresos en numerario se relacionaba con cierta compulsión a la que eran llevados los miembros de la clase rica para hacer frente a diferentes gastos acordes a (y para asegurar) su posición social: dotes, arriendo de haciendas de los ciudadanos huérfanos, compra de tierras, gastos de funerales, crisis temporarias, diferentes contribuciones y obligaciones impuestas por la ciudad, liturgias, etc. La necesidad de dinero y la presión social eran tales que muchos debieron hipotecar sus propiedades rurales (a través de los horoi hipotecarios) con el objetivo de conseguir préstamos para poder enfrentar este tipo de requerimientos (Finley, 1985; 2000, p. 85-102; Osborne, 2003, p. 192). En el mismo sentido se ha interpretado el arriendo de tierras públicas puesto que, además de haber sido un motivo de orgullo y prestigio de cara a la comunidad, respondía no a las necesidades de subsistencia, sino a la búsqueda de capital para cumplir con los requerimientos de la vida política, social y familiar de los sectores más acomodados (Osborne, 2003, p. 198-9; cf. Jameson, 1982). De forma análoga, se podría pensar que el arriendo de lotes privados era un modo a partir del cual los ricos podían, por un lado, obtener rentas en tanto que propietarios de la tierra (Burford, 1993, p. 177) pero, por otro lado, también utilizar ciertas ventajas económicas en tanto que arrendatarios: hacer un uso más eficiente de la fuerza de trabajo (principalmente esclava), diversificar su producción y obtener una ganancia rápida sin la necesidad de tener que hacer frente a 
las consecuencias de malas prácticas agrícolas propias de los arrendamientos de corto plazo (Osborne, 2003, p. 199$)^{29}$.

Pero no solo se debe pensar el arriendo de tierras en el contexto de lotes pequeños, dispersos y alejados o como un mecanismo utilizado por los ciudadanos ricos para hacer frente a sus necesidades de efectivo. También podemos suponer que el gran propietario ateniense pudo haber utilizado el arriendo como un modo de asegurarse mano de obra adicional a la fuerza de trabajo de los esclavos, especialmente para los períodos de alza en la actividad o para la realización de tareas especializadas, dos circunstancias para las cuales sabemos que era común el contrato de braceros asalariados (cf. Burford, 1993, p. 186-93; Wood, 1988, p. 71-2). De este modo, no resulta necesario pensar en el arriendo de tierras como un tipo de relación social en competencia con la explotación de los esclavos (como lo hace Wood, 1988, p. 64-80) ya que es probable que ambas se hayan dado de forma conjunta y vinculada. Si bien la evidencia de esto último es casi inexistente, se puede avanzar a través de la analogía con el caso de las haciendas esclavistas romanas en tanto estas, de acuerdo a la propuesta de Garnsey (1980; 1998, p. 91-106; cf. García Mac Gaw, 2006; Foxhall, 2007, p. 251) dependían para ser viables de la disponibilidad de trabajo libre principalmente en los períodos de mayor actividad agrícola. Así, el arriendo de tierras a familias campesinas podría haber permitido contar tanto con trabajadores para los momentos picos de demanda de trabajo como así también con encargados de la supervisión de la mano de obra esclava. En forma concurrente, Osborne (1995) ha planteado que en la agricultura griega existían dos momentos de alta demanda laboral; por un lado, el tiempo que correspondía al arado y la siembra y, por otro lado, la época en que se realizaba la cosecha. Tomando en cuenta el área total del Ática que podía ser aprovechada productivamente (Garnsey, 1985; cf. Osborne, 1985, p. 41 n.82; 1987, p. 46; Moreno, 2007, p. 3-33) y las distribución de la tierra entre las clases (Osborne, 1992), concluye que "it may have been possible for peasant farmers to reap their own cereal harvest with the aid of labour from the rest of the family (...) and from any normally domestic slaves". Sin embargo, para los terratenientes la situación habría sido bien distinta puesto que "the area where there would be a massive need for additional labour would be on the estates of the rich" (Osborne, 1995, p. 33). En definitiva, las condiciones habrían sido análogas a las de la villa romana y se espera que las respuestas también lo hayan sido: arriendo de tierras a familias de agricultores con el objetivo de tener disponible trabajo suplementario al de los esclavos para las tareas agrícolas y de control de los dependientes.

\section{LA MÍSTHOSIS ENTRE LA EXPLOTACIÓN Y LAS ESTRATEGIAS CAMPESINAS}

Ahora bien, en base a la evidencia analizada, resulta claro que la lógica que estructura el arriendo de tierras bajo las condiciones imperantes en la democracia ateniense responde más a la búsqueda de acceder a mano de obra extra o a ingresos en efectivo por parte de los terratenientes que a un modo estable de acceso a la tierra para los agricultores del Ática. Por otro lado, diversos especialistas han argumentado que la corta duración de los arriendos referidos en la documentación (de uno a tres años) constituye una marca de la debilidad de los agricultores frente a los propietarios (Wood, 1988, p. 183) o, incluso, permitiría postular un escenario de desesperación del arrendatario en tanto debían aceptar términos desfavorables en los acuerdos de tenencia (Osborne, 1988, p. 318; Valdés Guía, 2015, p. 188-9). Más aún, se podría argumentar que el empleo de misthós en la base de los términos que hacían referencia al arriendo de tierras determinaba que estos hayan quedado articulados en un campo semántico que implicaba a la noción de "salario"; y, se ha propuesto que, en particular durante el siglo IV a.C., aquel que dependía de un misthós para su reproducción social era un sujeto de condición degradada y que, a pesar de ser un hombre libre, se asimilaba a los esclavos (Plácido, 1989; 2008; Valdés Guía, 2015, p. 187) ${ }^{30}$. A pesar de lo anterior, creemos que la corta duración de los acuerdos de arriendo que unían al terrateniente con el colono no permitiría pensar en ellos como una forma sistemática, regular y estable de explotación de los agricultores (Burford, 1993, p. 178). 
Si bien resulta claro que en la relación de arriendo hay una transferencia de excedentes del productor directo hacia el terrateniente, creemos que la corta duración del vínculo podría también responder a las necesidades de la unidad doméstica campesina durante determinado momento de ciclo de vida familiar. A lo largo de su ciclo vital, una familia de agricultores enfrentaba variables cantidades de trabajo disponible y necesidades alimenticias por lo que, en algunas etapas, resultaba imperioso el acceso a tierras suplementarias durante cortos períodos de tiempo. A este respecto, Osborne (1988, p. 318-9) ha argumentado que los arriendos de uno a tres años que aparecen en los discursos de Lisias, resultaban demasiado breves para hacer frente a cualquier etapa del ciclo de vida familiar. Sin embargo, creemos que su interpretación no toma en cuenta la posibilidad de que una misma familia haya podido ir arrendando sucesivamente diferentes lotes por períodos muy cortos de tiempo ni el hecho de que las necesidades de tierras de una familia en un determinado momento de su ciclo vital pueden cambiar en muy poco tiempo. Gallant (1991, p. 27-30) ha reconstruido un modelo de ciclo de vida del hogar antiguo de 24 años (divididos en 8 trienios) basándose en múltiples datos procedentes tanto de la Grecia antigua como de la moderna y de otras sociedades mediterráneas. De acuerdo a su planteo, las necesidades de alimento (y por ende de tierras a ser sembradas) y las capacidades de trabajo de una unidad doméstica podían cambiar en lapsos muy breves; es decir, el tamaño de los campos de labranza necesarios para sostener a una unidad doméstica no es estático a lo largo del ciclo (Gallant, 1991, p. 83; cf. Chayanov, 1985, p. 47-68). Se trata de un cuadro dinámico en el que se pueden considerar diversos mecanismos de acceso a la tierra como ser herencia, dote, compra, fragmentación y arriendo (Gallant, 1991, p. 41-5, 82-7; cf. Gallego, 2009, p. 166 y 214). En este sentido, entonces, podemos pensar que los arriendos cortos pueden responder perfectamente a esas necesidades y capacidades cambiantes en una determinada fase del ciclo $^{31}$; como concluye Gallant (1991, p. 164), "depending on its economic circumstances or its life cycle phase, a household could find itself enmeshed in a number of different combinations of tenurial arrangements".

La coexistencia que se dio en la democracia ateniense entre, por un lado, un extendido grado de igualdad jurídico-política entre los ciudadanos (que inhibía el desarrollo de formas de explotación entre ciudadanos propias de las sociedades precapitalistas, es decir, basadas en la coacción extraeconómicas) y, por otro lado, un acceso diferenciado a la tierra agrícola (que suponía un polo con familias de labradores que contaban con menos tierras que las necesarias para la subsistencia y, conjuntamente, propietarios con más tierras de las que podían trabajar directamente con la mano de obra familiar) constituyen el marco a partir del cual hemos tratado aquí las relaciones de misthosis. La documentación analizada nos permite concluir que, por un lado, el arriendo de tierras constituyó una relación social bastante más extendida de lo que la historiografía de la democracia ateniense ha solido reconocer aunque, es necesario decirlo, estimar su incidencia cuantitativa es absolutamente imposible ${ }^{32}$. Por otro lado, el arriendo fue un mecanismo que vinculó a los terratenientes con aquellos ciudadanos que por el reducido tamaño de su propiedad, o por encontrarse en una determinada fase del ciclo de vida de su unidad doméstica, necesitaron tierras suplementarias para garantizar su supervivencia. A pesar de ello, se desprende de nuestro análisis que el arriendo no constituyó, dadas las condiciones sociales y políticas de la Atenas democrática, un mecanismo de explotación lo suficientemente estable y sistemático como para ser una de las bases sobre la que se estructuraba la riqueza de los sectores acaudalados de la ciudadanía (contra Osborne, 1988, p. 319; Wood, 1988, p. 78-80 y Kyrtatas, 2002, p. 152; cf. Foxhall, 2002, p. 216-7). Si bien es muy probable que una valoración negativa haya pesado sobre el hecho de que un ciudadano deba por necesidad económica entrar en este tipo de vínculos -recordemos su asociación con el misthós y la dificultad del pensamiento griego para distinguir la dominación de la explotación, cf. Kyrtatas, 2002; Paiaro, 2012-, la inclusión política de los agricultores como ciudadanos plenos y la no condicionalidad en el acceso a la tierra limitaron la posibilidad de explotar a los miembros del dêmos (incluso a los más pobres). A la vez, la democracia creó diversos mecanismos que restringieron la acumulación económica de los ciudadanos acaudalados y favorecieron formas de redistribución que dotaron a los pobres con la posibilidad de acceder a diversos recursos económicos sin la necesidad de integrarse en relaciones de subordinación. Era este el 
Diego Paiaro. “...tierras de labranza por rentas moderadas [Georgías epì metríais misthósesi]” (...

principal "problema" de la demokratía al que se enfrentó el Isócrates del Aeropagitico y los miembros de su clase a través de diversas estrategias a lo largo de los siglos V y IV a.C. Si en el contexto de finales de la Guerra del Peloponeso dicha estrategia buscaba reemplazar a la democracia por una oligarquía (como efectivamente se intentó con los golpes del 411 y 404 a.C.), Isócrates pertenece a otro momento en el que la oposición a la democracia se enmascaraba bajo la pugna por "regresar" a una pátrios politeía en la que, entre otros cambios, los agricultores comenzarían a acceder a la tierra bajo la condición de trabajarlas en beneficio de la élite. En última instancia, lo que se buscaba era escindir a los gobernantes de los productores (Wood, 2000, p. 220-7), es decir, anular ese rasgo que era característico (y por demás excepcional en el mundo precapitalista) de la demokratía de Atenas.

\section{REFERENCIAS}

Akrigg, B. (2019). Population and Economy in Classical Athens. Cambridge: Cambridge University Press.

Bearzot, C. (1980). Isocrate e il problema della democrazia. Aevum, 54(1), 113-131.

Brenner, R. (1988). Las raíces agrarias del capitalismo europeo. In T.H. Aston \& C.H.E. Philpin (eds.). El debate Brenner. Estructura de clases agraria y desarrollo económico en la Europa preindustrial (pp. 224-386). Barcelona: Editorial Crítica.

Buis, E. (2010). De la consolidación política a la ficción jurídica: aproximaciones al léxico del uso, la posesión y la propiedad privada en la antigüedad griega. En E. Conte \& M. Madero (eds.). Entre hecho y derecho: tener, poseer, usar, en perspectiva histórica (pp. 13-32). Buenos Aires: Manantial.

Burford, A. (1993). Land and Labour in the Greek World. Baltimore: Johns Hopkins University Press.

Canfora L. (1990). Isocrate e Teramene. En M. Mactoux \& E. Geny (eds.). Mélanges Pierre Lévêque. Tome 5: Anthropologie et société (pp. 61-64). Besançon: Université de Franche-Comté.

Carlsen, J. (2002). Estate Managers in Ancient Greek Agriculture. En K. Ascani, K. et. al. (eds.). Ancient History Matters. Studies Presented to Jens Erik Skydsgaard on his Seventieth Birthday (pp. 117-126). Roma: L'Erma di Bretschneider.

Cartledge, P. (1999). The Socratics' Sparta and Rousseau's. En S. Hodkinson \& A. Powell (eds.). Sparta. New Perspectives (pp. 311-337). Swansea: Classical Press of Wales.

Chantraine, P. (2009). Dictionnaire étymologique de la langue grecque. Histoire des mots. París: Éditions Klincksieck.

Chayanov, A.V. (1985). La organización de la unidad económica campesina. Buenos Aires: Nueva Visión.

Christ, M. (1990). Liturgy Avoidance and antidosis in Classical Athens. Transactions of the American Philological Association, 120, 147-169.

Cohen, E.E. (2000). The Athenian Nation. Princeton: Princeton University Press.

Davies, J.K. (1981). Wealth and the Power of Wealth in Classical Athens. Salem: The Ayer Company.

de Ste. Croix, G.E.M. (1988). La lucha de clases en el mundo griego antiguo. Barcelona: Editorial Crítica.

Finley, M.I. (1982). Esclavitud antigua e ideología moderna. Barcelona: Editorial Crítica.

Finley, M.I. (1984). Uso y abuso de la historia. Barcelona: Editorial Crítica.

Finley, M.I. (19852). Studies in Land and Credit in Ancient Athens, 500-200 BC. The Horos Inscriptions. New Brunswick: Transaction Publishers.

Finley, M.I. (1986a). La economía de la antigüedad. México: Fondo de Cultura Económica.

Finley, M.I. (1986b). El nacimiento de la política. Barcelona: Editorial Crítica.

Finley, M.I. (2000). La Grecia Antigua. Economía y sociedad. Barcelona: Editorial Crítica.

Foxhall, L. (2002). Access to Resources in Classical Greece. The Egalitarianism of the Polis in Practice. En P. Cartledge, E.E. Cohen \& L. Foxhall (eds.). Money, Labour and Land. Approaches to the Economies of Ancient Greece (pp. 209-220). Londres \& Nueva York: Routledge.

Foxhall, L. (2007). Olive Cultivation in Ancient Greece. Seeking the Ancient Economy. Oxford: Oxford University Press. 
Gallant, T.W. (1991). Risk and Survival in Ancient Greece. Reconstructing the Rural Domestic Economy. Stanford: Stanford University Press.

Gallego, J. (2005). Campesinos en la ciudad. Bases agrarias de la pólis griega y la infantería hoplita. Buenos Aires: Ediciones del Signo.

Gallego, J. (2007). Farming in the Ancient Greek World: How should the small free producers be defined? Studia Humaniora Tartuensia, 8(A.3). Recuperado de https://www.ut.ee/klassik/sht/2007/gallegol.pdf

Gallego, J. (2009). El campesinado en la Grecia antigua. Una historia de la igualdad. Buenos Aires: EUDEBA.

Gallego, J. (2016). El campesinado y la distribución de la tierra en la Atenas del siglo IV a.C. Gerión, 34, 43-75.

Gallego, J. (2017). Riqueza y desigualdad en la Atenas del siglo IV a.C. En M. Campagno, J. Gallego \& C. García Mac Gaw (comps.). Capital, deuday desigualdad. Distribuciones de la riqueza en el Mediterráneo Antiguo (pp.79-102). Buenos Aires: Miño y Dávila.

Gallego, J. (2018a). Filolaconismo y política oligárquica en Atenas a finales del siglo V a.C. Habis, 49, 43-63.

Gallego, J. (2018b). Los labradores del Ática durante el siglo IV y la crisis del ideal del campesino-ciudadano. En J. Pascual, I. Borja Antela Bernárdez \& D. Gómez Castro (coords.). Cambio y pervivencia. El mundo griego en el siglo IV a.C. (pp. 41-54). Madrid: Ediciones de la Universidad Autónoma de Madrid.

Gallego, J. \& Valdés Guía, M. (2014). El campesinado ático y el desarrollo de la democracia ateniense. Buenos Aires: Miño y Dávila Editores.

García Mac Gaw, C. (2006). La transición del esclavismo al feudalismo y la villa esclavista. Dialogues d'histoire ancienne, 32(2), 27-41.

Garnsey, P. (1980). Non-Slave Labour in the Roman World. En P. Garnsey (ed.). Non-Slave Labour in the GrecoRoman World (pp. 34-47). Cambridge: Cambridge Philological Society.

Garnsey, P. (1985). Grain for Athens. En P. Cartledge, \& E. Harvey (eds.). Crux. Essays Presented to G.E.M. de Ste. Croix on his 75th Birthday (pp. 62-75). Londres: Imprint Academic.

Garnsey, P. (1998). Cities, Peasants and Food in Classical Antiquity. Essays in Social and Economic History. Cambridge: Cambridge University Press.

Hansen, M.H. (1989). Solonian Democracy in Fourth Century Athens. Classica et Mediaevalia, 40, 71-99.

Harding, P. (1974). The Theramenes Myth. Phoenix, 28(1), 101-111.

Harrison, A.R.W. (1968). The Law of Athens. The Family and the Property. Oxford: Clarendon Press.

Hodkinson, S. (2005). The Imaginary Spartan Politeia. En M. H. Hansen (ed.). The Imaginary Polis (pp. 222-281). Copenhague: The Royal Danish Academy of Sciences and Letters.

Isager, S. \& Skydsgaard, J.E. (1992). Ancient Greek Agriculture. An Introduction. Londres: Routledge.

Jameson, M.H. (1982). The Leasing of Land in Rhamnous. Hesperia Supplements, 19, 66-74.

Jones, N.F. (2004). Rural Athens under the Democracy. Filadelfia: University of Pennsylvania Press.

Jordović, I. (2014). The Origins of Philolaconism: Democracy and Aristocratic Identity in Fifth-Century BC Athens. Classica et Mediaevalia, 65, 127-154.

Kehoe, D. (2012). Tenancy, Greek and Roman. En R. S. Bagnall, K. Brodersen, C. B. Champion, A. Erskine \& S. R. Huebner (eds.). The Encyclopedia of Ancient History. Wiley-Blackwell. Doi: https://10.1002/978144433838 6.wbeah 13244

Kyrtatas, D. (2002). Domination and Exploitation. En P. Cartledge, E.E. Cohen \& L. Foxhall (eds.). Money, Labour and Land. Approaches to the Economies of Ancient Greece (pp. 140-155). Londres \& Nueva York: Routledge.

Leese, M. (2016/7). Lysias and a Forgotten Law on the Administration of Orphans' Estates in Classical Athens. Dike, 19/20, 107-124.

Liddell, H. \& Scott, R. (1940). A Greek-English Lexicon. Oxford: Clarendon Press.

MacDowell, D.M. (1978). The Law in Classical Athens. Londres: Thames \& Hudson.

Marx, K. (1989). Formas que preceden a la producción capitalista. En K. Marx \& E. Hobsbawm. Formaciones económicas precapitalistas (pp. 67-119). Mexico: Siglo XXI Editores. 
Diego Paiaro. “...tierras de labranza por rentas moderadas [Georgías epì metríais misthósesi]” (...

McHugh, M. (2017). The Ancient Greek Farmstead. Oxford: Oxbow Books.

Meiggs, R. \& Lewis, D.M. (eds.) (1989). A Selection of Greek Historical Inscriptions to the End of the Fifth Century BC. Oxford: Clarendon Press.

Millet, P. (2002). La economía. In R. Osborne (ed.). La Grecia clásica, 500-323 a.C. (pp. 31-62). Barcelona: Editorial Crítica.

Mirhady, D. \& Too, Y. (2000). Isocrates I. Austin: University of Texas Press.

Moreno, A. (2007). Feeding the Democracy. The Athenian Grain Supply in the Fifth and Fourth Centuries B.C. Oxford: Oxford University Press.

Mossé, C. (1978). Le thème de la patrios politeia dans la pensée grecque du IVe siècle. Eirene, 16, 81-89.

Mossé, C. (1979). Comment s'élabore un mythe politique: Solon, « père fondateur » de la démocratie athénienne. Annales ESC, 34(3), 425-437.

Mossé, C. (1980). El trabajo en Grecia y Roma. Madrid: Akal.

Ober, J. (1989). Mass and Elite in Democratic Athens. Rhetoric, Ideology, and thePower of the People. Princeton: Princeton University Press.

Osborne, R. (1985). Demos: The Discovery of Classical Attika. Cambridge: Cambridge University Press.

Osborne, R. (1987). Classical Landscape with Figures. The Ancient Greek City and its Countryside. Londres: George Philip.

Osborne, R. (1988). Social and Economic Implications of the Leasing of Land and Property in Classical and Hellenistic Greece. Chiron, 18, 279-323.

Osborne, R. (1992). 'Is it a Farm?' The Definition of Agricultural Sites and Settlements in Ancient Greece. En B. Wells (ed.). Agriculture in Ancient Greece (pp. 21-27). Estocolmo: Paul Åström Förlag.

Osborne, R. (1995). The Economics and Politics of Slavery at Athens. En A. Powell (ed.). The Greek World (pp. 27-43). Londres: Routledge.

Osborne, R. (2003). Orgullo y prejuicio, sensatez y subsistencia. Intercambio y sociedad en la ciudad griega. En J. Gallego (ed.). El mundo rural en la Grecia antigua (pp. 185-209). Madrid: Akal.

Paiaro, D. (2011a). Las "paradojas" de la democracia. Igualdades y asimetrías en la Atenas Clásica (Tesis doctoral, Universidad de Buenos Aires). Recuperada de http://repositorio.filo.uba.ar/handle/filodigital/1702

Paiaro, D. (2011b). Las reformas de Solón y los límites de la coacción extraeconómica en la Atenas arcaica. Sociedades Precapitalistas. Revista de Historia Social, 1(1). Recuperado de https://www.sociedadesprecapitalistas.fahce.un lp.edu.ar/article/view/v1n1a3

Paiaro, D. (2012). Relaciones de dependencia en la Atenas clásica, entre la explotación y la dominación. Trabajos y Comunicaciones, 38, 153-183.

Paiaro, D. (2013). Relaciones de dependencia rural y constitución de la singularidad ateniense durante el arcaísmo. En A. Sapere (ed.). Nuevas aproximaciones a la antigüedad grecolatina II (pp. 82-105). Buenos Aires: Editorial Rhesis.

Paiaro, D. \& Requena, M. (2015). “Muchas veces pegarías a un ateniense creyendo que era un esclavo”... (PS-X, 1, 10): espacios democráticos y relaciones de dependencia en la Atenas Clásica. En A. Beltrán, I. Sastre \& M. Valdés (eds.). Los espacios de la esclavitudy la dependencia desde la Antigüedad. Homenaje a Domingo Plácido. Actas del XXXV coloquio del GIREA (pp. 153-170). Besançon: Presses Universitaires de Franche-Comté.

Paiaro, D. \& Requena, M. (2018). Entre la «masa ociosa» y la «explotación económica»: los ciudadanos pobres de la democracia ateniense. Nuevas reflexiones sobre un viejo problema. En J. Cortadella, O. Olesti Vila \& C. Sierra Martín (eds.). Lo viejo y lo nuevo en las sociedades antiguas: homenaje a Alberto Prieto. XXXVI Coloquio del GIREA (pp. 159-176). Besançon: Presses Universitaires de Franche-Comté.

Papazarkadas, N. (2011). Sacred and Public Land in Ancient Athens. Oxford: Oxford University Press.

Pernin, I. (2014). Les baux ruraux en Grèce ancienne. Corpus épigraphique et étude. Lyon: Maison de l'Orient et de la Méditerranée - Jean Pouilloux. 
Plácido, D. (1989). «Nombres de libres que son esclavos...» (Póllux, III, 82). En AA.VV. Esclavos y semilibres en la Antigüedad clásica (pp. 59-79). Madrid: Universidad Complutense de Madrid.

Plácido, D. (1997). La sociedad ateniense. La evolución social en Atenas durante la guerra del Peloponeso. Barcelona: Editorial Crítica.

Plácido, D. (2008). Las relaciones clientelares en la evolución de la democracia ateniense. Circe de clásicos y modernos, $12,225-242$.

Requena, M.J. (2011). La situación agraria ateniense del siglo IV a.C. y la «crisis» de la pólis. En C. Ames et al. (eds.). Historia Antigua. III Jornadas Nacionales/II Jornadas Internacionales (pp. 323-334). Córdoba: Universidad Nacional de Córdoba. Recuperado de http://publicaciones.ffyh.unc.edu.ar/index.php/antigua/article/view/35 $0 / 354$.

Requena, M.J. (2013a). Isócrates, Areopagítico: ¿Un pensamiento crítico de la democracia o una democracia pensada críticamente?. Actas y Comunicaciones del Instituto de Historia Antigua y Medieval, 9. Recuperado de http://rev istascientificas.filo.uba.ar/index.php/AcHAM/article/view/1094/

Requena, M.J. (2013b). ¿Se puede hablar de un "patronazgo estatal”? Liturgias y misthophoría en la Atenas Clásica. Sociedades Precapitalistas, 2(2). Recuperado de https://www.sociedadesprecapitalistas.fahce.unlp.edu.ar/article /view/SPv02n02a04

Requena, M.J. (2014). Lógicas de patronazgo y democracia en la pólis ateniense. En E. Dell'Elicine, H. Francisco, P. Miceli \& A. Morin (orgs.). Clientelismo, parentesco y cultura jurisdiccional en las sociedades precapitalistas (pp. 47-79). Los Polvorines: Universidad Nacional de General Sarmiento.

Requena, M.J. (2016). Esclavos y labradores. Relaciones de dependencia en la Atenas del siglo IV a. C. (Tesis Doctoral, Universidad de Buenos Aires). Recuperada de http://www.repositorio.filo.uba.ar/handle/filodigital/6111

Sancho Rocher, L. (2004). Los “moderados” atenienses y la implantación de la oligarquía. Corrientes políticas en Atenas entre 411 y 403 a.C. Veleia, 21, 73-98.

Sancho Rocher, L. (2008). Democracia frente a populismo en Isócrates. Klio: Beitrage zur alten geschichte, 90(1), 36-61.

Sancho Rocher, L. (2016). Terámenes: ¿̇traidor, "coturno" o moderado?. En F. Marco Simón, F. Pina Polo \& J. Remesal Rodríguez (eds.). Autorretratos: la creación de la imagen personal en la antigüedad (pp. 13-40). Barcelona: Edicions de la Universitat de Barcelona.

Shanin, T. (1971). Peasantry: Delineation of a Sociological Concept and a Field of Study. European Journal of Sociology, $12,289-300$.

Shipton, K. (2000). Leasing and Lending. The Cash Economy in Fourth-Century BC Athens. Bulletin of the Institute of Classical Studies Supplement, 74.

Todd, S.C. (2000). Lysias. Austin: University of Texas Press.

Valdés Guía, M. (2015). La renovación de la dependencia en el s.IV: los espacios de thetes y misthotoi. En A. Beltrán, I. Sastre \& M. Valdés (eds.). Los espacios de la esclavitudy la dependencia desde la Antigüedad. Homenaje a Domingo Plácido. Actas del XXXV coloquio del GIREA (pp. 183-199). Besançon: Presses Universitaires de Franche-Comté.

Valdés Guía, M. (2018). De los ptochoi homéricos a los del s.IV: lo viejo y lo nuevo, mendicidad y evergesía. En J. Cortadella, O. Olesti Vila \& C. Sierra Martín (eds.). Lo viejo y lo nuevo en las sociedades antiguas: homenaje a Alberto Prieto. XXXVI Coloquio del GIREA (pp. 103-119). Besançon: Presses Universitaires de Franche-Comté.

Walbank, M.B. (1991). Leases of Public Lands. The Athenian Agora, 19, 147-207.

Wood, E.M. (1988). Peasant-citizen and Slave. The Foundations of Athenian Democracy. Londres: Verso Books.

Wood, E.M. (2000). Democracia contra capitalismo. La renovación del materialismo histórico. México: Siglo Veintiuno Editores.

Wood, E.M. (2002). Landlords and Peasants, Masters and Slaves: Class Relations in Greek and Roman Antiquity. Historical Materialism, 10(3), 17-69.

Zelnick-Abramovitz, R. (2004). Settlers and Dispossessed in the Athenian Empire. Mnemosyne, 57, 325-345.

Zimmern, A. (1961). The Greek Commonwealth. Politics and Economics in Fifth-Century Athens. Nueva York: Galaxy Book. 


\section{Zuchtriegel, G. (2018). Colonization and Subalternity in Classical Greece: Experience of the Nonelite Population.} Cambridge: Cambridge University Press.

\section{Notas}

1 De hecho, sufrió en el año 354-3 a.C. un proceso de antídosis (15.4-5). Acerca del sistema de liturgias y del mecanismo jurídico conocido como antídosis, ver Christ (1990).

2 Cf. Sancho Rocher (2004) que argumenta en contra de la existencia de una corriente política "moderada" fundada sobre la figura de Terámenes. La pátrios politeía resultaba, en el siglo IV a.C., frecuentemente asociada a la figura del legislador Solón y éste, al establecimiento de una supuesta pátrios demokratía. Como planteaba Finley (1984, p. 73), “en Atenas al final del siglo V, la oligarquía cesó de ser un problema práctico. Sin embargo, permaneció la oposición intelectual a la democracia y en esos círculos... la apelación a la constitución ancestral conservó vitalidad”. Cf. Mossé (1978; 1979) y Hansen (1989).

3 Para Esparta como una (buena) democracia, ver Bearzot (1980); cf. Hodkinson (2005, p. 232-4).

4 Sobre el filolaconismo como posicionamiento de una parte de la elite ateniense, ver Cartledge (1999, p. 113-4), Hodkinson (2005, p. 223), Jordović (2014) y Gallego (2018a).

5 Nos basamos en la traducción de traducción de J.M. Guzmán Hermida (1982, Madrid: Gredos).

6 Para el patronazgo (y sus límites), Requena (2013b; 2014). Relaciones de dependencia en la demokratía, Paiaro (2012).

7 Las fuentes utilizan generalmente el sustantivo misthosis y el verbo misthóo. Son términos con origen en misthós, comúnmente, "salario" (Liddell \& Scott, 1940, s.v. misthosis y misthóo; Chantraine, 2009, s.v. misthós). Para una reconstrucción de la relación entre misthosis y misthós, MacDowell (1978, p. 140-1).

8 No consideraremos las tierras de los huérfanos puestas en arriendo por la ciudad (Arist. Ath. Pol. 56.6-7), generalmente arrendadas por la elite en busca de prestigio; cf. Finley (1985, p. 38-43), Osborne (1988, p. 308-10 y 315-6; 2003, p. 192); Leese (2016/7).

9 Utilizamos a lo largo del artículo el concepto de campesino/campesinado (peasant/peasantry) de una forma general, no específica y meramente descriptiva para referirnos a los productores rurales que se basaban principalmente en el trabajo familiar y, en este sentido, podría operar como sinónimo de agricultor, labrador, productor familiar, pequeño productor rural, etc. (o, en inglés, householder, small producer, small freeholder, smallholder, etc.). Somos conscientes que el uso de campesino conlleva una serie de implicancias que no lo hacen totalmente certero para describir las condiciones bajo las cuales los labradores vivían y trabajaban, en particular, en Atenas clásica. La cuestión nodal consiste en que dicho concepto tiene como uno de sus fundamentos el hecho de definir al campesinado como un grupo social políticamente subordinado que es obligado a producir un surplus, un excedente, apropiado por otros sectores sociales (la ciudad, los terratenientes o el Estado). Si bien la bibliografía es extensa, la definición proporcionada por Shanin (1971) sintetiza los puntos básicos. Para Grecia, ha sido debatido el uso de los conceptos de campesino (peasant) y granjero (farmer); ver Gallego (2007; 2009, p. 181-92). En relación a los propios términos griegos de georgós y autourgós y sus complejidades, ver las puntualizaciones de Burford (1993, p. 15, 167-72).

10 A fines prácticos, en este trabajo hablamos de terratenientes para indicar a aquel sector social dentro del grupo de los ciudadanos que controlaba una cantidad de tierras superior a las que podían ser explotadas en base a su propia fuerza laboral familiar. La disposición de estos lotes agrícolas, junto con otros bienes y actividades económicas, les permitían situarse, en mayor o menor medida, dentro de lo que podríamos definir como la élite, la aristocracia, la clase ociosa o, de acuerdo a la definición de de Ste. Croix (1988, p. 142), la clase de los propietarios. Cf. Davies (1981, p. 38-72), Ober (1989, p. 192-6). Un marco general sobre terratenientes y campesinos en la antigüedad clásica en Finley (1986a, p. 113-49).

11 Para el siglo V a.C., ver nuestras estimaciones en Paiaro (2011, p. 117-76) donde también se encuentra resumido el debate historiográfico. Para el siglo IV a.C., ver el reciente trabajo de Gallego (2017) en el cual se cita la bibliografía pertinente sobre la cuestión.

12 Este punto requeriría una explicación detallada pero, por una cuestión de espacio, remitimos a los trabajos en los que desarrollamos esta línea interpretativa (Paiaro, 2011b; 2013). En palabras de Finley (1982, p.114), "El campesinado, había obtenido su libertad personal y su derecho a la tierra no sin luchas, en [las] que también había conquistado la ciudadanía, el derecho de ser miembro de la comunidad”. Para Wood (2002, p. 20-1), “The peasant-citizen was certainly a «distinctive characteristic» of Athenian society (...) ...Attic peasants (...) enjoyed an unusual degree of freedom from various forms of exploitation by landlord and state. The civic status of the small producer limited the two principal forms of surplus extraction to which peasants, in particular, have historically been subject: rent and tax. The democracy (...) restricted the wealth and power of landlords by limiting the opportunities for concentrating property and by protecting small producers from various forms of personal dependence -slavery, serfdom, debt-bondage". 
13 Sobre la ausencia de propiedad privada en la pólis, ver: Burford (1993, p. 15-55). Finley (1985, p. 54) había ya destacado la inexistencia en la lengua griega de un término específico. Cf. Harrison (1968, p. 200-5) y MacDowell (1978, p. 133). Cf. Buis (2010).

14 Un contraste entre el agricultor ateniense y los campesinos de la Europa feudal puede resultar útil. Según propone Brenner (1988, p. 271-2) el campesino medieval y de comienzos de la Edad Moderna disponía de la "posesión” (ambigua y conflictiva) de la tierra marcada por la "condicionalidad de la propiedad feudal”. Dicha no propiedad plena los "obligaba a acogerse a la «protección» de algún señor" lo que hacía que la "posesión” campesina quedara "limitada por el poder señorial”. Es esa condicionalidad de la "posesión” campesina (que trae aparejado relaciones de subordinación) aquello que se encontraba ausente en el caso ateniense.

15 De acuerdo al planteo de Wood (1988, p. 97), "The relationship would not be juridical or political, in the sense that it would not be based on the «lender's» privileged juridical status or political superiority, nor on the 'borrower's' juridical dependence or political subjection. It would be an «economic» relationship, based on the lender's superior property”. Para volver a la época feudal, Brenner (1988, p. 272-3) identifica esta misma situación cuando plantea que los feudales podían obtener "un excedente de los campesinos sin tener que recurrir a (...) la compulsión extraeconómica, esto es, únicamente sobre la base de la propiedad de la tierra” puesto que cuando los agricultores disponían de pocas tierras "no tuvieron más elección que arrendar tierra y/o enajenar su fuerza de trabajo".

16 La cuestión de las relaciones de explotación, los aspectos "económicos" y "extraeconómicos" los hemos trabajado en Paiaro (2011a; 2011b; 2012; 2013) y Paiaro \& Requena (2018). Al respecto Plácido (1989, p. 69-70 y 76) afirma que "la situación del pobre ateniense del siglo IV, que tenía que realizar trabajos serviles y que participa en las luchas del demos por conservar la politeia y la libertad, lo que significa evitar que sobre él caiga la coacción fundamentada en las nuevas estructuras políticas buscadas por el pensamiento de Isócrates, Platón o Aristóteles. La esclavización basada en la necesaria trophé [alimentación], sin la utilización de medios extraeconómicos, está presente en Atenas, tanto en la época arcaica, antes o en los inicios de la democracia, como en el siglo IV, en la crisis de la democracia. Pero la carencia de medios extraeconómicos de coacción está siempre en tensión dinámica con la existencia de los mismos..." (en p. 76).

17 Cf. Finley (1985, p. 95-6), Jameson (1982), Walbank (1991), Osborne (1987, p. 36-7, 41, 46-7, 71-4; 1988, p. 281-92), Shipton (2000, p. 39-45 y 80-2), Jones (2004, p. 27-34), McHugh (2017, p. 15-6, 39-40). Para el corpus epigráfico, ver Pernin (2014, p. 31-97). Recientemente Papazarkadas (2011, p. 51-75) ha publicado un estudio monográfico tratando las tierras pertenecientes a las tribus (p. 106-11), los demos (p. 112-26 y 150-5), las fratrías (p. 166-70), los géne (p. 171-91) y los orgeiônes (p. 191-7, 204-4) con un útil catálogo que sintetiza los datos disponibles (p. 299-325).

18 Las principales monografías sobre la historia agraria griega dedican poco espacio al arriendo de tierras privadas; cf. Burford (1993, p. 177-181), Jones (2004, p. 27-34), Isager y Skidsgaard (1992, p. 154-5) y McHugh (2017, p. 39-42). Se debe destacar al respecto el trabajo de Osborne (1988).

19 "El agricultor con tierras en arriendo y el aparcero fueron un fenómeno del mundo helenístico y de la Roma imperial (...) no de la ciudad-estado" había afirmado Finley (1986b, p. 50).

20 Para una revisión crítica de estas tesis, resultan útiles los trabajos de Requena (2011;2016, p. 134-90), Gallego \& Valdés Guía (2014, p. 213-32), Gallego (2016; 2018b) y Akrigg (2019, p. 246-7).

21 Cf. sin embargo, una referencia de Teofrasto (Thphr. CP 2.11.3) en la que se parece aludir a la existencia de contratos escritos que estipulan determinadas condiciones; cf. Burford (1993, p. 181). En general, para cualquier aspecto de la economía rural griega la evidencia es muy fragmentaria (Foxhall, 2007, p. 28).

22 Traducción de S. Lambert \& J. Schneider (Attic Inscriptions Online), recuperado de https://www.atticinscriptions.co $\mathrm{m} /$ inscription/IGI3/1-add-p-935.

23 Traducción de J.J. Torres Esbarranch (1991, Madrid: Gredos).

24 Osborne (1988, p. 311) ha hecho notar la ausencia de quejas acerca de la dificultad para encontrar arrendatarios en el registro literario.

25 El acusado declaró tener "influencia y dinero", ser propietario de diferentes fincas, de una cantidad indeterminada de esclavos y haber pagado liturgias como trierarca y corego (Lys. 7.21, 24, 31, 34). Sobre las liturgias, ver más arriba la n.1. Cf. sin embargo la postura de Millett (2002, p. 31-3) para quien se trataría de un "granjero" y no un "ciudadano muy rico".

26 Foxhall (2007, p. 74-5) se ha opuesto a esta interpretación considerando el caso como una excepción: "Here the land in question may have been rented out because it was being 'held in trust' for the exiled oligarch Periander (the owner before it was confiscated by the state) by his friends". Sin embargo, creemos que el hecho de que la tierra haya sido comprada y vendida en varias oportunidades luego de la confiscación quitaría valor al argumento de la autora.

27 A este respecto, Cohen (2000, p. 126-9) ha argumentado que la población rural no estaba fijada a su demo de origen, tenía gran movilidad y los residentes no ciudadanos eran un fenómeno mucho más extendido de lo que suele pensarse. Cf. las críticas de Gallego (2005, p. 110 n. 81; cf. Gallego \& Valdés Guía, 2014, p. 44-5 n. 40). Burford (1993, p. 179) destaca que el arriendo de metecos podría ser un modo de subsanar la prohibición legal de poseer tierras que pesaba sobre ellos dirigiendo inversiones de capital obtenidas desde otras actividades hacia la agricultura. 
Diego Paiaro. “...tierras de labranza por rentas moderadas [Georgías epì metríais misthósesi]” (...

28 Cf. el idílico caso de Iscómaco, presentado por Jenofonte (X. Oec. 11.15-8), que era capaz de vigilar las tareas agrícolas durante la mañana y regresar a la ciudad para el almuerzo; cf. Carlsen (2002, p. 119).

$29 \mathrm{Al}$ respecto, Jenofonte planteaba que: "Lo cierto es que quien sólo presta atención a la belleza corporal pienso que se asemeja al que ha tomado un terreno en arriendo [misthoméno khôron], que no se preocupa de mejorarlo y aumentar su valor, sino de sacar la mayor cantidad de frutos de la cosecha" (X. Smp. 8.25; cf. de Ste. Croix, 1988, p. 149-50).

30 Hemos argumentado (Paiaro \& Requena, 2015) que es necesario ver en esta asimilación que aparece en diferentes fuentes ([Jenofonte], Jenofonte, Platón, Aristóteles, etc.) más un componente ideológico de la élite que una descripción de la realidad social ateniense.

31 A modo de ejemplo, en el segundo trienio del ciclo vital nos situamos frente a un hogar extendido horizontal (descendencia) y verticalmente (corresidencia de parientes): los cónyuges junto con su descendencia, un sobreviviente de la generación de los padres (generalmente la madre viuda) y un hermano solitario. Este tipo de configuración requeriría de 3,5 ha. para alcanzar la producción de subsistencia. Sin embargo, en poco tiempo se desestructuraría (Gallant, 1991, p. 30) y en la siguiente etapa (habiendo muerto ya la madre y casado el hermano constituyendo un nuevo oîkos) los requerimientos de tierras serían sustancialmente menores (2,5 ha.). Entre los años 15 y 18 del ciclo, se pasa de 4 a 3 ha. para sostener a la unidad doméstica.

32 Gallant (1991, p. 164) ha planteado que "a sizable, but not precisely quantifiable, sector of the peasantry obtained access to land by contracting some type of conditional tenure agreement with large land-owners”; cf. Burford (1993, p. 177).

\section{BY-NC-SA}

